\title{
CHILDREN'S EXPOSURE TO INDOOR AIR IN SCHOOLS: IMPACT ON WHEEZING
}

\author{
JULIANA P. SÁ, PEDRO T. B. S. BRANCO, MARIA C. M. ALVIM-FERRAZ, \\ FERNANDO G. MARTINS \& SOFIA I. V. SOUSA \\ Laboratory for Process Engineering, Environment, Biotechnology and Energy (LEPABE), \\ Faculty of Engineering, University of Porto, Portugal
}

\begin{abstract}
Wheezing is a common symptom in childhood and has been associated with air pollution. Children spend a large part of their time in school, this being the most important indoor environment apart from home. However, studies on the impact of children's indoor air pollution exposure at schools on respiratory health are scarce. Thus, this study aimed to assess the impact of children's exposure to indoor air pollution in a total of five urban nursery and primary schools on active wheezing. Multivariate logistic regression models were used to estimate the associations, adjusted for sex, age group (pre-school/primary school) and parental history of asthma. A microenvironmental modelling approach was used to estimate indoor air pollution exposure to each of the pollutants exceeding legislation limit values $\left(\mathrm{CO}_{2}\right.$, formaldehyde and $\left.\mathrm{PM}_{2.5}\right)$, as the sum of the product of time spent by the child in different indoor school microenvironments and the time-averaged concentration measured in each microenvironment. Measurements were performed in 11 classrooms, two bedrooms and two canteens in Porto, Portugal. A total of 164 completed parent-reported questionnaires derived from the International Study of Asthma and Allergies in Childhood allowed to identify active wheezing (at least one wheeze episode in the previous 12 months) in $16.5 \%$ of the studied children. Although not statistically significant, the studied children's exposure to indoor air pollution in nursery and primary schools seemed to be associated with an increase in the odds of having active wheezing especially for $\mathrm{PM}_{2.5}(\mathrm{OR}=1.57, p$-value $=0.675)$. These results highlight the importance of applying indoor air pollution mitigation measures in nursery and primary schools. The impacts of those measures, on both indoor air quality and children's respiratory health, should be evaluated in future studies.

Keywords: indoor air pollution, nursery and primary schools, children, wheezing.
\end{abstract}

\section{INTRODUCTION}

Children constitute a sensitive population to environmental contaminants' exposure, including indoor air pollutants, since their lungs and immune system are still under development and they have a relatively higher amount of air inhalation. Effectively, evidence has been made that indoor air pollution (IAP) impacts children's respiratory health [1].

Wheezing is a very common health respiratory symptom on childhood and one of the most common causes of morbidity and hospitalization among infants and young children, and respiratory infections [2]. Approximately $25-30 \%$ of infants have at least one wheezing episode, and nearly half of the children have a history of wheezing by six years of age [3]. Wheezing is often considered the expression of an acute infection, being also frequently associated with other respiratory diseases [4]. In fact, wheezing could be an indicator of asthma and chronic obstructive pulmonary disease, being these the most common causes of wheezing [5]. Besides, asthma and wheezing are among the most frequent reasons for children's visits to paediatricians [6].

Apart from home, school is the most important indoor environment for children, in where they spend a great part of their day. However, indoor air quality (IAQ) in schools has been less studied than in other buildings, and consequently the attention given to the adverse children's health effects in these environments is scarce [1]. Nevertheless, in Portugal, indoor air quality limit values are defined for new and existent commercial and services buildings, 
including schools, for pollutants such as particulate matter $\left(\mathrm{PM}_{2.5}\right.$ and $\left.\mathrm{PM}_{10}\right)$, carbon dioxide, carbon monoxide, volatile organic compounds, formaldehyde and radon [7].

Existing literature focused on the association between children's exposure to indoor air pollutants and respiratory health is also limited, and mostly focusing on asthma, thus neglecting childhood wheezing although it is more common and easier to diagnose [8]-[13].

Moreover, information on the prevalence of childhood wheezing covering Portuguese children remains scarce. Furthermore, the impact of exposure to IAP in nursery and primary schools on childhood wheezing has not been extensively studied. Thus, this study mainly aimed to assess the impact of children's exposure to IAP in urban nursery and primary schools on active wheezing.

\section{METHODOLOGY}

The study population consisted of pre-schoolers (3-5 years old) and primary school children (6-10 years old) attending three nurseries and two primary schools involved in the INAIRCHILD project [14]. These schools were located in urban context in Porto district, in the north of Portugal $\left(41^{\circ} \mathrm{N}, 8^{\circ} \mathrm{W}\right)$.

According to Branco et al. [15], a microenvironmental modelling approach seemed to be the best methodology to assess individual children's exposure to air pollution, whereby it was adopted for this study. Based on the concepts of calculating exposure introduced by Fugas [16], Duan [17], [18] and Ott [19], the present work resorted to eqn (1) to estimate individual children's exposure

$$
E_{i}=\sum_{j=1}^{J} C_{i j} t_{i j}
$$

where $E_{i}$ is the exposure of the $i^{\text {th }}$ individual, $C_{i j}$ is the concentration of the pollutant measured in the $j^{\text {th }}$ microenvironment of the $i^{\text {th }}$ individual, $t_{i j}$ is the time spent by the $i^{\text {th }}$ individual in the $j^{\text {th }}$ microenvironment, and $J$ is the number of different microenvironments (ME) considered.

The adopted approach was based on both continuous monitoring of indoor air pollutants in the distinct indoor ME and data of time-location patterns for a day (daily exposure). Therefore, data from daily time-location patterns, i.e. the time spent by each individual (child) in each indoor ME (classrooms, bedrooms and canteens) was obtained from the school timetable and validated by the educator/teacher of the class. In turn, indoor continuous sampling of $\mathrm{CO}_{2}$, formaldehyde and $\mathrm{PM}_{2.5}$ were carried out during occupancy periods in 11 classrooms, two bedrooms and two canteens, and hourly mean values were calculated. Detailed characterization of sampling and IAQ of these ME was previously described [20] and conclusions were that $\mathrm{CO}_{2}$, formaldehyde and $\mathrm{PM}_{2.5}$ have exceeded Portuguese legislation limit values [7], thus they were selected to integrate the IAP exposure evaluation in the present study. After being calculated, IAP exposure was dichotomized in "under" or "above" limit values by considering the limit values in the Portuguese legislation for IAQ as the cut-off, namely: (i) $2250 \mathrm{mg} / \mathrm{m}^{3}$ for $\mathrm{CO}_{2}$ (plus $30 \%$ of margin of tolerance as no mechanical ventilation system was working in the room); (ii) $100 \mu \mathrm{g} / \mathrm{m}^{3}$ for formaldehyde; and (iii) $25 \mu \mathrm{g} / \mathrm{m}^{3}$ for $\mathrm{PM}_{2.5}$ (plus $100 \%$ of margin of tolerance as no mechanical ventilation system was working in the room), for the association with active wheezing.

A total of 164 ISAAC-derived questionnaires (International Study of Asthma and Allergies in Childhood derived questionnaires) were completed by parents or guardians of children attending the studied ME, accepted to participate in the study and signed an informed consent according to the Helsinki Declaration developed by the World Medical Association, allowing collecting individual information of sex, age, parental history of asthma, and respiratory symptoms, namely wheezing and dyspnoea. Active wheezing (reporting at least 
one wheeze episode in the previous 12 months) was considered the main health outcome in this study.

Moreover, this study was approved by both the Ethics Commission of Universidade do Porto and the Ethics Commission for Health of Centro Hospitalar Universitário de São João, Porto.

Descriptive statistics were used to express the characteristics of individuals, IAP exposure and health outcomes. Multivariate logistic regression models were used to estimate the odds ratios (OR) of the associations between IAP exposure and active wheezing, adjusted for age group (pre-schoolers or primary school children), sex and parental history of asthma. Statistical analyses were performed with R software version 3.5.3 [21]. The level of statistical significance was set at 0.05 .

\section{RESULTS AND DISCUSSION}

\subsection{Study site and population}

Children's daily indoor exposures to $\mathrm{CO}_{2}$, formaldehyde and $\mathrm{PM}_{2.5}$ were summarized (minimum, median, mean, maximum and interquartile range (IQR)) in Table 1.

Table 1: Summary of children daily exposures to $\mathrm{CO}_{2}$, formaldehyde and $\mathrm{PM}_{2.5}$ in the studied microenvironments.

\begin{tabular}{|l|c|c|c|c|c|}
\hline & Minimum & Median & Mean & Maximum & IQR \\
\hline $\mathrm{CO}_{2}\left(\mathrm{mg} / \mathrm{m}^{3}\right)$ & 1706 & 2641 & 2579 & 3877 & 487.4 \\
\hline Formaldehyde $\left(\mu \mathrm{g} / \mathrm{m}^{3}\right)$ & 19.96 & 64.58 & 71.67 & 277.7 & 73.38 \\
\hline $\mathrm{PM}_{2.5}\left(\mu \mathrm{g} / \mathrm{m}^{3}\right)$ & 20.52 & 32.56 & 41.64 & 67.88 & 38.10 \\
\hline
\end{tabular}

When comparing to the limit values of the Portuguese legislation for IAQ, the majority of the individuals were exposed to indoor air pollutants above that threshold. In fact, the worst case was $\mathrm{PM}_{2.5}$ (92.4\% of individuals exposed to concentrations above the threshold), followed by $\mathrm{CO}_{2}(61.0 \%)$ and finally formaldehyde $(26.8 \%)$.

Characteristics of the studied population (mean age 5.4 years old), including respiratory symptoms, were summarized in Table 2 .

The study population was gender balanced, including exactly the same number of male and female children. The number of children not born in Portugal was residual. Important to consider is the number of the studied children having at least one asthmatic parent $(23.9 \%)$. The prevalence of ever wheezing and dyspnoea (at least once in lifetime) was $28.7 \%$ and $8.5 \%$, respectively, while the prevalence of active wheezing and dyspnoea (at least one episode in the previous year) was $16.4 \%$ and $5.5 \%$, respectively. Effectively, in both ever and previous year, the prevalence of wheezing was higher than the prevalence of dyspnoea, highlighting the importance of that respiratory outcome. From those reporting active wheezing $(16.4 \%)$, one to three diurnal attacks in the previous year were frequently reported $(15.2 \%)$, while only $1.2 \%$ reported more than 12 diurnal attacks in the same period. On the other hand, nocturnal episodes of wheeze were not so common as diurnal, as the majority of those reporting active wheezing did not present any nocturnal attack $(9.1 \%)$, while $3.0 \%$ and $4.3 \%$ reported having less than one and at least one nocturnal attack of wheezing per week, respectively. Exercise induced and speech-limiting wheeze attacks were not so common, being presented in only $2.4 \%$ and $1.8 \%$ of the study population, respectively. 
Table 2: Characterization of study population, including respiratory heath symptoms (with respective $95 \%$ confidence intervals).

\begin{tabular}{|c|c|c|}
\hline & $\%$ & 95\% Confidence interval \\
\hline \multicolumn{3}{|l|}{ Age group } \\
\hline Pre-schooler & 61.6 & $54.1-69.0$ \\
\hline Primary school children & 38.4 & $31.0-45.9$ \\
\hline \multicolumn{3}{|l|}{ Sex } \\
\hline Male & 50.0 & $42.3-57.7$ \\
\hline Female & 50.0 & $42.3-57.7$ \\
\hline \multicolumn{3}{|l|}{ Born in Portugal } \\
\hline Yes & 99.4 & $98.2-100.0$ \\
\hline No & 0.6 & $0.0-1.8$ \\
\hline \multicolumn{3}{|l|}{ Asthmatic parent } \\
\hline No & 76.1 & $69.5-82.6$ \\
\hline Yes & 23.9 & $17.4-30.5$ \\
\hline \multicolumn{3}{|l|}{ Ever symptoms (lifetime prevalence) } \\
\hline Wheeze & 28.7 & $21.7-35.6$ \\
\hline Dyspnoea & 8.5 & $4.3-12.8$ \\
\hline \multicolumn{3}{|l|}{ Active symptoms (last year) } \\
\hline Wheeze & 16.4 & $10.8-22.1$ \\
\hline Dyspnoea & 5.5 & $2.0-9.0$ \\
\hline \multicolumn{3}{|l|}{ Prevalence of wheeze in the last year } \\
\hline \multicolumn{3}{|l|}{ Attacks number } \\
\hline None & 0.0 & $0.0-0.0$ \\
\hline 1 to 3 & 15.2 & $9.7-20.7$ \\
\hline 4 to 12 & 0.0 & $0.0-0.0$ \\
\hline$>12$ & 1.2 & $0.0-2.9$ \\
\hline \multicolumn{3}{|l|}{ Nocturnal attacks number } \\
\hline None & 9.1 & $4.7-13.6$ \\
\hline$<1$ night/week & 3.0 & $0.4-5.7$ \\
\hline$\geq 1$ night/week & 4.3 & $1.2-7.4$ \\
\hline Exercise induced & 2.4 & $0.1-4.8$ \\
\hline Speech-limiting attacks & 1.8 & $0.0-3.9$ \\
\hline
\end{tabular}

Active wheezing prevalence in the present study could be compared with the prevalence reported in previous studies as they used a similar methodology (data reported in ISAACderived questionnaires). In primary school children from Viseu, Portugal, Martins et al. [22] reported a slightly lower active wheezing prevalence $(11.7 \%)$ when compared with that of the present study. Also for primary school children (aged 7-9 years old) from two municipalities in Western Cape Province, South Africa, Olaniyan et al. [8] reported a slightly lower prevalence of active wheezing (12.9\%) than in the present study. In another study in Portugal, Branco et al. [12] reported an active wheezing prevalence of $17.1 \%$ for children with less than 5 years old attending nursery schools in Porto and Bragança districts, which 
was very similar to the prevalence calculated in the present study. On the other hand, Norbäck et al. [23] reported an active wheezing prevalence of 19.7\% in pre-schoolers (aged 3-6 years old) from day care centres in seven cities of China, which was slightly higher than that calculated in the present study.

\subsection{Modelling associations between IAP exposure and active wheezing}

Table 3 summarizes the results from the multivariate logistic regression models representing the association between exposure to $\mathrm{CO}_{2}$, formaldehyde and $\mathrm{PM}_{2.5}$, and active wheezing, namely odds ratios (OR), correspondent $95 \%$ confidence intervals $(95 \% \mathrm{CI})$ and $p$-values. A separate model was built for each indoor air pollutant studied. Crude (unadjusted) and adjusted models were obtained.

Table 3: Crude and adjusted odds ratios (OR and aOR), and respective 95\% confidence intervals $(95 \% \mathrm{CI})$ and significance ( $p$-values) of the associations between exposure to $\mathrm{CO}_{2}$, formaldehyde and $\mathrm{PM}_{2.5}$, and active wheezing.

\begin{tabular}{|l|c|c|c|c|}
\hline & $\begin{array}{c}\text { crude OR } \\
(\mathbf{9 5 \%} \text { CI) }\end{array}$ & $\begin{array}{c}\text { crude } \\
\text { p-value }\end{array}$ & $\begin{array}{c}\text { aOR } \\
(\mathbf{9 5 \%} \text { CI) }\end{array}$ & $\begin{array}{c}\text { adjusted } \\
\boldsymbol{p} \text {-value }\end{array}$ \\
\hline Exposed to CO2 & $0.83(0.36-1.95)$ & 0.676 & $0.71(0.29-1.73)$ & 0.449 \\
\hline Age group: Pre-schooler & $3.08(1.10-8.66)$ & $\mathbf{0 . 0 3 3 *}$ & $2.79(0.96-8.07)$ & $\mathbf{0 . 0 4 4 *}$ \\
\hline Sex: Male & $2.64(1.08-6.49)$ & $\mathbf{0 . 0 3 4 *}$ & $2.27(0.90-5.70)$ & 0.074 \\
\hline Asthmatic parent: Yes & $1.89(0.76-4.66)$ & 0.168 & $1.85(0.72-4.73)$ & 0.207 \\
\hline Exposed to formaldehyde & $1.30(0.52-3.24)$ & 0.580 & $1.09(0.41-2.90)$ & 0.861 \\
\hline Age group: Pre-schooler & $3.08(1.10-8.66)$ & $\mathbf{0 . 0 3 3 *}$ & $2.61(0.89-7.63)$ & 0.064 \\
\hline Sex: Male & $2.64(1.08-6.49)$ & $\mathbf{0 . 0 3 4 *}$ & $2.25(0.90-5.64)$ & 0.076 \\
\hline Asthmatic parent: Yes & $1.89(0.76-4.66)$ & 0.168 & $1.82(0.71-4.70)$ & 0.223 \\
\hline Exposed to PM2.5 & $1.66(0.20-13.9)$ & 0.640 & $1.57(0.17-14.4)$ & 0.675 \\
\hline Age group: Pre-schooler & $3.22(1.10-9.47)$ & $\mathbf{0 . 0 3 3 *}$ & $2.49(0.81-7.67)$ & 0.097 \\
\hline Sex: Male & $3.59(1.22-10.6)$ & $\mathbf{0 . 0 2 0 *}$ & $3.07(1.01-9.31)$ & $\mathbf{0 . 0 3 7 *}$ \\
\hline Asthmatic parent: Yes & $1.23(0.43-3.49)$ & 0.702 & $1.07(0.36-3.20)$ & 0.906 \\
\hline
\end{tabular}

$95 \% \mathrm{CI}=95 \%$ of confidence interval; $\mathrm{OR}=$ odd ratio; aOR $=$ adjusted odd ratio; $*$ Significant at $p$-value $<0.05$ calculated by likelihood ratio (LR) test.

Although not statistically significant, children's exposure to indoor $\mathrm{PM}_{2.5}$ in nursery and primary schools seemed to be associated with an increase in the odds of having active wheezing in childhood $(\mathrm{aOR}=1.57, p$-value $=0.675)$. Although less significant, similar results were found for formaldehyde exposure $(\mathrm{aOR}=1.09, p$-value $=0.861)$. On the other hand, although also not statistically significant $\mathrm{CO}_{2}$ presented an opposite behaviour $(\mathrm{aOR}=0.71, p$-value $=0.449)$, which was expected as $\mathrm{CO}_{2}$ is not an air pollutant per se, although it is usually used as a global indicator of air change rate (ventilation).

Previous studies in the literature reported that PM has a negative impact on human respiratory health, namely in children [24], [25]. Moreover, short-term $\mathrm{PM}_{2.5}$ exposures in schools were linked to increased hospital admissions and emergency department visits for 
respiratory effects, particularly wheezing [10]. In all models, being a male child, a preschooler or having at least one asthmatic parent increased the odds of having active wheezing.

These results were in accordance with some previous studies in the literature, namely with a study in primary school children (aged 9-11 years old) from Malta that also reported a direct association between wheezing and high exposure to indoor formaldehyde and $\mathrm{PM}_{2.5}$ [26]. Rawi et al. [10] stated significant associations between wheezing and indoor $\mathrm{PM}_{2.5}$ concentrations in preschools (aged 5-6 years old) from Selangor, Malaysia and no significant association between indoor $\mathrm{CO}_{2}$ concentration and respiratory symptoms. Another study performed both in primary schools and homes of schoolchildren living in Malaysia (Kuala Lumpur and Negeri Sembilan), reported no significant associations between exposure to indoor $\mathrm{PM}_{2.5}$ and current wheezing [9]. A Portuguese study in public primary schools also located in Porto concluded that higher exposure to $\mathrm{PM}_{2.5}$ increased the odds of wheeze among children, and that indoor exposure to formaldehyde was related with wheeze in the past year [11]. Another Portuguese study performed in day care centres from Porto and Lisbon (mean age of participants: 3.1 years old) described a significant relation between $\mathrm{CO}_{2}$ concentration and reported wheezing in the previous 12 months [27]. However, these comparisons with other previous studies should be interpreted with care, mainly because some of those considered IAP concentrations rather than IAP exposures, and others were carried out also in other microenvironments rather than only nursery and/or primary schools (e.g. home).

The main strength of the present study was the use of a ME modelling approach to estimate children's individual exposure to IAP in nursery and primary schools. On the other hand, a limited number of nursery and primary schools, and consequently a limited number of participants (children) were the main limitations of this study.

\section{CONCLUSIONS}

As far as the author's knowledge goes, this was the first study assessing the impact of children's exposure to IAP $\left(\mathrm{CO}_{2}\right.$, formaldehyde and $\left.\mathrm{PM}_{2.5}\right)$ in urban nursery and primary schools on active wheezing, using a ME modelling approach to estimate IAP exposure.

This study concluded that children was very often exposed to levels of IAP higher than legislated inside nursery and primary schools, namely $\mathrm{PM}_{2.5}, \mathrm{CO}_{2}$ and formaldehyde. The prevalence of childhood active wheezing was $16.4 \%$, in accordance with previous studies in the literature for similar study populations. Although not statistically significant, the studied children's exposure to IAP in nursery and primary schools, especially $\mathrm{PM}_{2.5}(\mathrm{OR}=1.57$, $p$-value $=0.675)$, seemed to be associated with an increase in the odds of having active wheezing. These results highlighted the importance of applying IAP mitigation measures in nursery and primary schools to reduce its levels, which is expected to mitigate the negative effects on children's respiratory health.

Future developments include the enrolment of more schools and participants (children), as well as to extend the analysis to physician diagnosed respiratory health outcomes, namely asthma. Moreover, the impact of mitigation measures should also be evaluated in future studies.

\section{ACKNOWLEDGEMENTS}

This work was financially supported by: project UID/EQU/00511/2019 - Laboratory for Process Engineering. Environment. Biotechnology and Energy (LEPABE) funded by national funds through FCT/MCTES (PIDDAC); project PTDC/SAU-SAP/121827/2010 funded by FCT, COMPETE, QREN and EU; and project POCI-01-0145-FEDER-032391, funded by FEDER funds through COMPETE2020 - Programa Operacional Competitividade e Internacionalização (POCI) and by national funds (PIDDAC) through FCT/MCTES. 


\section{REFERENCES}

[1] Annesi-Maesano, I., Baiz, N., Banerjee, S., Rudnai, P., Rive, S. \& Group, S., Indoor air quality and sources in schools and related health effects. Journal of Toxicology and Environmental Health, Part B, 16(8), pp. 491-550, 2013.

[2] Emenius, G., Svartengren, M., Korsgaard, J., Nordvall, L., Pershagen, G. \& Wickman, M., Indoor exposures and recurrent wheezing in infants: A study in the BAMSE cohort. Acta Paediatrica, 93(7), pp. 899-905, 2004.

[3] Weiss, L.N., The diagnosis of wheezing in children. American Family Physician, 77(8), pp. 1109-1114, 2008.

[4] Bousquet, J. \& Kaltaev, N., Global Surveillance, Prevention and Control of Chronic Respiratory Diseases: A Comprehensive Approach, World Health Organization, 2007.

[5] Ng, M.C.W. \& How, C.H., Recurrent wheeze and cough in young children: Is it asthma? Singapore Medical Journal, 55(5), pp. 236-241, 2014.

[6] Hu, F.B., Persky, V., Flay, B.R., Zelli, A., Cooksey, J. \& Richardson, J., Prevalence of asthma and wheezing in public schoolchildren: Association with maternal smoking during pregnancy. Annals of Allergy, Asthma and Immunology, 79(1), pp. 80-84, 1997.

[7] Portaria number 353-A/2013, Legislation from Ministérios do Ambiente, Odenamento do Território e Energia, da Saúde e da Solidariedade, Emprego e Segurança Social Diário da República - 1 ${ }^{\text {a }}$ Série, N. 253(9), pp. 6644(2)-6644, 2013.

[8] Olaniyan, T. et al., Asthma-related outcomes associated with indoor air pollutants among schoolchildren from four informal settlements in two municipalities in the Western Cape Province of South Africa. Indoor Air, 29(1), pp. 89-100, 2019.

[9] Abidin, Z.E., Semple, S., Rasdi, I., Ismail, S.N.S. \& Ayres, J.G., The relationship between air pollution and asthma in Malaysian schoolchildren. Air Quality, Atmosphere and Health, 7(4), pp. 421-432, 2014.

[10] Rawi, N.A.M.N., Jalaludin, J. \& Chua, P.C., Indoor air quality and respiratory health among Malay preschool children in Selangor. BioMed Research International, 2015.

[11] Madureira, J. et al., Indoor air quality in schools and its relationship with children's respiratory symptoms. Atmospheric Environment, 118, pp. 145-156, 2015.

[12] Branco, P.T.B.S. et al., Asthma prevalence and risk factors in early childhood at Northern Portugal. Revista Portuguesa de Pneumologia, 22(3), pp. 146-150, 2016.

[13] Raaschou-Nielsen, O. et al., Long-term exposure to indoor air pollution and wheezing symptoms in infants. Indoor Air, 20(2), pp. 159-167, 2010.

[14] Sousa, S.I.V., Ferraz, C., Alvim-Ferraz, M.C.M., Vaz, L.G., Marques, A.J. \& Martins, F.G., Indoor air pollution on nurseries and primary schools: impact on childhood asthma: Study protocol. BMC Public Health, 12(1), p. 435, 2012.

[15] Branco, P.T.B.S., Alvim-Ferraz, M.C.M., Martins, F.G. \& Sousa, S.I.V., The microenvironmental modelling approach to assess children's exposure to air pollution: A review. Environmental Research, 135, pp. 317-332, 2014.

[16] Fugas, M., Assessment of total exposure to an air pollutant. Proceeding of the International Conference on Environmental Monitoring, Las Vegas Nevada Institute of Electrical and Electronic Engineers Inc., New York, 1975.

[17] Duan, N., Micro-environment types: A model for human exposure to air pollution. Stanford University, Department of Statistics, 1981.

[18] Duan, N., Models for human exposure to air pollution. Environment International, 8(1-6), pp. 305-309, 1982.

[19] Ott, W.R., Concepts of human exposure to air pollution. Environment International, 7(3), pp. 179-196, 1982. 
[20] Sá, J., Branco, P., Alvim-Ferraz, M., Martins, F. \& Sousa, S., Evaluation of low-cost mitigation measures implemented to improve air quality in nursery and primary schools. International Journal of Environmental Research and Public Health, 14(6), p. 585, 2017.

[21] R Core Team, R: A language and environment for statistical computing. R Foundation for Statistical Computing, Vienna, Austria. www.R-project.org/. Accessed on: Apr. 2019.

[22] Martins, P. et al., Airways changes related to air pollution exposure in wheezing children. European Respiratory Journal, 39(2), pp. 246-253, 2012.

[23] Norbäck, D. et al., Sources of indoor particulate matter (PM) and outdoor air pollution in China in relation to asthma, wheeze, rhinitis and eczema among pre-school children: Synergistic effects between antibiotics use and $\mathrm{PM}_{10}$ and second hand smoke. Environment International, 125, pp. 252-260, 2019.

[24] Jones, A.P., Indoor air quality and health. Atmospheric Environment, 33(28), pp. 4535-4564, 1999.

[25] Nandasena, S., Wickremasinghe, A.R. \& Sathiakumar, N., Indoor air pollution and respiratory health of children in the developing world. World Journal of Clinical Pediatrics, 2(2), pp. 6-15, 2013.

[26] Fsadni, P., Bezzina, F., Fsadni, C. \& Montefort, S., Impact of school air quality on children's respiratory health. Indian Journal of Occupational and Environmental Medicine, 22(3), pp. 156-162, 2018.

[27] Carreiro-Martins, P. et al., $\mathrm{CO}_{2}$ concentration in day care centres is related to wheezing in attending children. European Journal of Pediatrics, 173(8), pp. 1041-1049, 2014. 